\title{
Aprender ciências por investigação na educação pré-escolar: exploração de uma proposta didática em contexto de formação inicial de educadores
}

\author{
Inquiry-based science learning in preschool education: exploring a \\ didactic proposal in the context of initial teacher training
}

\author{
Paulo Varela (pibvarela@ie.uminho.pt) \\ CIEC - Instituto de Educação, Universidade do Minho, Braga - Portugal
}

\begin{abstract}
Resumo: Nos últimos anos, a literatura em educação em ciências tem demonstrado um renovado interesse na aprendizagem das ciências por investigação nos vários níveis educativos, incluindo na educação pré-escolar. Porém, a insegurança dos educadores em relação às ciências tem limitado e empobrecido as oportunidades de aprendizagem das crianças. Neste sentido, temos vindo a promover um processo de formação inicial de educadores de infância, orientado para o desenvolvimento de competências científicas e didáticas inerentes à abordagem das ciências por investigação. Durante a formação, os estudantes planificam propostas didáticas e exploram-nas com as crianças nos seus respetivos contextos educativos. A partir de um desses casos, designadamente uma sequência de atividades com balões, este artigo descreve essa experiência formativa e apresenta a análise do processo de exploração das atividades, promovido por estudantes, em formação, com crianças da educação pré-escolar. A análise, que incide no diário elaborado pelos estudantes, vai apresentando as aprendizagens e os processos desenvolvidos pelas crianças no ato de aprender, permitindo verificar que estas são capazes de assumir uma atitude científica de procura do saber, quando devidamente estimuladas pelo educador e envolvidas em experiências de aprendizagem interessantes e significativas.
\end{abstract}

Palavras-chave: ciências por investigação; educação pré-escolar; proposta didática.

Abstract: In recent years, literature on science education has reflected a renewed interest in the inquiry-based science learning across the various educational levels, including preschool education. However, the educators' insecurity in relation to sciences has limited and impoverished children's learning opportunities. Given this scenario, we have been promoting a process of initial training for preschool educators that focuses on the development of the scientific and didactic skills inherent to a inquiry-based approach to sciences. During the training, students will plan out didactic proposals and explore them with the children in their educational context. Taking one of these cases, namely a sequence of activities involving balloons, this article describes that formative experience and presents the analysis of the process of exploring those activities, developed by the students in training, with preschool children. The analysis, which focuses on the diary prepared by the students, presents the learning outcomes and the processes developed by the children in the act of learning, allowing to verify that they are able to take on a scientific attitude of seeking knowledge when properly stimulated by the educator and engaged in interesting and meaningful learning experiences.

Key Words: inquiry-based science education; preschool education; didactic proposal. 


\section{INTRODUÇÃ̃}

As crianças, desde muito cedo, manifestam uma curiosidade natural para explorarem e darem sentido ao meio que as rodeia (TRUNDLE, 2015). Elas gostam de observar e pensar sobre o mundo natural (ESHACH; FRIED, 2005), manifestando um grande entusiasmo em conhecer, descobrir, agir, dialogar e experimentar. Pode-se inclusivamente referir que as ciências, enquanto método de estudo da Natureza, têm o seu equivalente na criança, na sua natural e incontida apetência para explorar e descobrir o meio em que vive, com vista a construir a sua própria visão do mundo. As primeiras experiências de aprendizagem em ciências devem aproveitar e potenciar estas qualidades naturais das crianças, pois elas constituem o suporte prévio necessário para que assumam um papel ativo na aprendizagem (FRENCH, 2004). Trata-se de utilizar esse desejo natural de conhecer o mundo "[...] como plataforma sobre a qual possam construir ferramentas de pensamento que lhes permitam compreender como as coisas funcionam, e pensar por eles mesmos" (FURMAN, 2009, p. 7). As atividades de ciências que estimulam a investigação ou a procura do saber são cruciais para o desenvolvimento e a manutenção dessa curiosidade (SMITH, 2016), bem como para o desenvolvimento de competências de processos científicos simples (FRENCH; WOODING, 2013), como, por exemplo, observar, fazer perguntas, prever, experimentar, interpretar e discutir com os outros os resultados das suas descobertas (GERDE et al., 2013). Estas competências são fundamentais não só para que as crianças comecem a construir uma melhor compreensão do mundo, mas também a entender a natureza da ciência, a investigação e o raciocínio científico e a desenvolver atitudes mais positivas e conscientes face à ciência. Como refere Harlen (2012), através da investigação desenvolvem o seu conhecimento e compreensão da ciência e em ciência e, ao mesmo tempo, aprendem a investigar, ou seja, aprendem a aprender. Sem este começo, "as experiências posteriores carecerão da base para a construção de competências e compreensão necessárias à aprendizagem posterior e ao longo da vida" (HARLEN, 2014, p. 18). Neste sentido, concordamos com Reis (2008), quando refere que educar as crianças em ciências não significa transformá-las em "pequenos cientistas", nem "fazer de conta" que reproduzem o mundo real. Trata-se, segundo o autor, de:

(...) fomentar, desde a mais tenra idade, a capacidade de observar, de questionar, de comparar e justificar, para estabelecer, a partir do vivido, do observado e do experienciado, patamares de conhecimento, provisório mas sustentado, que irão erguer a pouco e pouco a arquitetura conceptual, analítica e estruturante que faz dos humanos seres pensantes, capazes de pensar cientificamente a realidade, isto é, de a interpretar com fundamento e de questionar com pertinência. (REIS, 2008, p. 10).

Assim, a educação científica, nos anos correspondentes à educação pré-escolar, é de grande importância, pois é suscetível de desenvolver as bases do pensamento científico 
e uma compreensão básica dos fenómenos naturais, que serão fundamentais nas aprendizagens científicas ulteriores das crianças (ESHACH; FRIED, 2005; TRUNDLE; SAÇKES, 2012). Uma abordagem significativa das ciências na educação pré-escolar pode também promover a motivação das crianças para a ciência em fases posteriores do seu percurso escolar (PATRICK; MANTZICOPOULOS, 2015). Resultados de alguns estudos recentes da psicologia cognitiva, referidos por Trundle e Saçkes (2012), indicam que as primeiras experiências de aprendizagem são essenciais para o desenvolvimento cognitivo das crianças e limitadas experiências e estímulos podem fazer com que elas não desenvolvam todo o seu potencial.

As características do mundo moderno requerem também uma educação científica precoce, para que os futuros cidadãos estejam preparados para viverem nele, assumindose como sujeitos participativos, críticos e informados na tomada das suas decisões. Segundo Fiolhais, "uma criança que não fique próxima da ciência na idade dos "porquês" [...] dificilmente estará preparada para a vida, que, atualmente, se vê cada vez mais dependente da ciência e da tecnologia" (2012, p. 59). A este propósito é de recordar a Declaração final da Conferência Mundial sobre "Ciência para o século XXI: um novo compromisso", realizada em 1999 pela UNESCO em Budapeste, onde se afirma que:

\footnotetext{
o acesso ao conhecimento científico, a partir de uma idade muito precoce, faz parte do direito à educação de todos os homens e mulheres, e que a educação científica é de importância essencial para o desenvolvimento humano, para a criação de capacidade científica endógena e para que tenhamos cidadãos participantes e informados" (UNESCO, 2005, p. 29).
}

Apesar das ciências constituírem uma área de conteúdo essencial na educação de infância, vários estudos continuam a evidenciar as limitadas oportunidades que as crianças deste nível educativo dispõem para aprenderem ciências, comparativamente com outras áreas de saber (NAYFELD et al., 2011; SAÇKES, 2014; DOMÉNECH et al., 2016; GERDE et al., 2018). Porém, quando tais oportunidades existem, a exploração das ciências resume-se frequentemente à observação e manipulação de materiais e objetos, com pouca orientação e intencionalidade educativa por parte dos educadores (GERDE et al., 2013). Apesar de não se conhecerem estudos recentemente realizados no nosso país, temos também observado, com frequência, em vários contextos de educação pré-escolar, práticas que se limitam a promover a familiarização das crianças com factos e experiências marcadamente lúdicas ou a realização de explorações e manipulações casuísticas de objetos e materiais, numa suposta pedagogia de "descoberta", em ambos os casos, sem nenhuma intencionalidade educativa específica. Também Martins et al. (2009) referem que:

ao nível da educação pré-escolar, a educação em ciências é, muitas vezes, relegada para segundo plano, sendo amiúde pouco enriquecedoras as 
experiências de aprendizagem proporcionadas às crianças, e observando-se um fosso entre aquilo que elas são capazes de fazer e compreender e as experiências a que têm acesso no jardim de infância e também no seu meio familiar" (p. 14-15).

O insuficiente domínio do conhecimento científico e didático específico tem sido uma das causas associada a esta realidade, originando nos ptofissionais dos primeiros níveis educativos baixa autoconfiança ou insegurança em relação às ciências e à sua exploração com as crianças (HAMLIN; WISNESKI, 2012; GERDE et al., 2018). Desta forma, tendem normalmente a usar atividades em que se sentem "seguros" e que, muitas vezes, empobrecem as oportunidades de aprendizagem das crianças (HARLEN; ALLENDE, 2009).

Ora, a exploração e aprendizagem investigativa das ciências implica, em termos didáticos específicos, a combinação de renovadas ações dos educadores/professores e das próprias crianças, bem como o seu envolvimento conjunto na investigação de questões relevantes sobre como o mundo funciona (PRISCINET, 2014). Entre outras ações, os educadores/professores devem: proporcionar às crianças oportunidades para explorarem materiais ou investigarem fenómenos desconhecidos; organizar discussões, em pequeno e grande grupo, sobre as ações planeadas ou realizadas, para que as crianças possam identificar possíveis alternativas ou melhorias; fornecer o acesso a ideias e procedimentos alternativos, através da discussão e de fontes de pesquisa, como a internet; propor tarefas desafiadoras, fornecendo o suporte (scaffolding) necessário, para que as crianças possam experimentar e operar num nível cognitivo mais elevado; ensinar determinadas técnicas, incluindo o uso seguro de instrumentos, objetos e materiais; incentivar as crianças, através de comentários e questionamentos, a avaliarem a consistência das suas ideias à luz das evidências disponíveis e a considerarem explicações alternativas apresentadas por outras; ajudar as crianças a efetuarem registos das suas observações, de forma a apoiarem e a reverem as aprendizagens efetuadas; incentivar a reflexão crítica sobre como aprenderam e como isso pode ser aplicado em situações futuras de aprendizagem; usar o questionamento para encorajar o uso de competências de investigação (IAP, 2006).

Por seu lado, as crianças devem, no processo de investigação: reunir evidências através da observação, da experimentação ou do uso de outras fontes; procurar resposta para questões que identificaram como suas, mesmo que introduzidas pelo educador/professor; levantar outras questões que podem originar novas investigações; elaborar previsões com base nas suas ideias ou no que descobriram; dialogar entre si ou com o educador/professor sobre o que estão a observar ou a investigar; exprimir-se usando termos científicos e representações apropriadas; sugerir formas de testarem as suas ideias ou as dos outros para encontrarem evidências que suportem essas mesmas ideias; participar no planeamento de investigações para responderem a questões 
específicas; utilizar instrumentos de medição, objetos e materiais de forma adequada e com confiança; avaliar a validade e utilidade de diferentes ideias em relação à evidência; considerar ideias diferentes das suas; refletir de forma autocrítica sobre os processos e os resultados da investigação (IAP, 2006).

\section{OBJETIVOS}

Conscientes das dificuldades anteriores, temos vindo a promover, com os estudantes da formação inicial de educadores de infância, um processo de formação, orientado para a construção e desenvolvimento de conhecimentos científicos e didáticos específicos para a abordagem das ciências por investigação. O processo formativo proporciona-lhes a oportunidade de planificarem propostas didáticas de atividades investigativas de ciências e de as explorarem com as crianças nos seus respetivos contextos educativos. É com base num desses casos, uma sequência de atividades de aprendizagem com balões, que tem subjacente o princípio físico da "conservação da quantidade de movimento", realizada por uma dupla de estudantes do Mestrado em Educação Pré-Escolar da Universidade do Minho (Portugal), que se pretende, neste artigo, (a) descrever essa experiência formativa e (b) identificar os processos de aprendizagem, realizados pelas crianças, durante a exploração das atividades, promovida pelos estudantes com um grupo de 22 crianças de 4 e 5 anos de idade da educação préescolar.

\section{CONTEXTOS E PROCESSOS DE FORMAÇÃO}

O processo formativo ocorre, normalmente, no âmbito da unidade curricular de "Iniciação à Matemática e às Ciências na Educação de Infância", lecionada no $1 .^{\circ}$ semestre do $1 .^{\circ}$ ano do plano de estudos daquele mestrado, e desenvolve-se em dois contextos: na universidade e nos jardins de infância.

$\mathrm{Na}$ universidade, a formação baseia-se em situações e exemplos concretos, que integram o conhecimento científico e didático (APPLETON, 2007), nomeadamente: a) a exploração, com os estudantes, de atividades de investigação similares às previstas para as crianças da educação pré-escolar. Desta forma, a formação assume uma natureza análoga à perspetiva de exploração investigativa das ciências, preconizada para as crianças (BULUNUZ, 2012). Segundo Sá, "não há forma de fazer os professores e educadores compreenderem em que consiste um processo de aprendizagem que nunca vivenciaram, que não seja fazê-los passar por tal processo na qualidade de aprendizes" (2003, p. 57); b) a análise de diários de atividades e do visionamento de gravações vídeo, resultantes de experiências pedagógicas realizadas pelo docente da unidade curricular, 
autor deste artigo, em diversos contextos de educação de infância, como alternativa à incorporação de representações das práticas dos educadores nos processo formativo promovido na universidade (ZEICHNER, 2010).

Uma outra forma de integrar o conhecimento científico e didático na abordagem das ciências por investigação é, segundo Heywood e Parker (2010), fazer com que os estudantes, em formação inicial, planifiquem propostas de atividades, passando pelas seguintes etapas: a) estudar o tópico científico subjacente às atividades planificadas, os principais conceitos e as possíveis dificuldades conceituais; b) conhecer as metas de aprendizagem definidas no currículo; c) testar essas propostas de atividades que integram conceitos científicos e a abordagem didática. Atendendo a estas etapas, os estudantes planificam também atividades de ciências, face aos interesses das crianças e às necessidades identificadas nos diversos contextos de jardim de infância, que tiveram oportunidade de observar, no âmbito da unidade curricular de "Observação, Documentação e Avaliação na Educação de Infância" ". Essas planificações contêm, para além do material necessário e dos objetivos de aprendizagem, uma síntese do conhecimento científico sobre o tópico planificado e indicações didáticas sobre como devem explorar as atividades e induzir nas crianças uma atitude reflexiva e investigativa, em relação às atividades de aprendizagem propostas.

Nos jardins de infância, em estreita colaboração com as educadoras, os estudantes, em duplas, exploram com as crianças as atividades planificadas no contexto de formação anterior. Trata-se de proporcionar "experiências de campo" orientadas e devidamente articuladas com o conhecimento teórico-didático, de modo a que se efetive a aprendizagem docente que a elas está associada (ZEICHNER, 2010). Durante a exploração das atividades assumem, simultaneamente, o papel de investigadores, utilizando a observação participante para obterem uma melhor compreensão das diferentes perspetivas das crianças que se geram e reconstroem no ato de aprender (LATORRE, 2004). Os dados gerados são registados preferencialmente sob duas formas complementares: as notas de campo e as gravações áudio. Estes dados em bruto materializaram-se, posteriormente, sob a forma de narrativas completas e detalhadas dos acontecimentos mais relevantes ocorridos no grupo de crianças (GRAUE; WALSH, 2003) - os diários das atividades. Para além de um método de registo de dados, a escrita dos diários constitui uma estratégia promotora da reflexão sobre a ação pedagógica promovida com as crianças (ZABALZA, 2004), assumindo-se como um importante elemento formativo na constituição da identidade docente (LEITE, 2019).

\footnotetext{
${ }^{1}$ Esta unidade curricular prevê duas semanas para os estudantes observarem determinadas dimensões pedagógicas nos contextos da prática profissional, uma sensivelmente a meio e outra no final do semestre.
} 


\section{A SEQUÊNCIA DE ATIVIDADES DE APRENDIZAGEM COM BALÕES}

$\mathrm{Na}$ aprendizagem das ciências, os balões proporcionam a realização de uma grande diversidade de atividades interessantes e desafiadoras do pensamento e da ação das crianças. Assim, partindo também do interesse pelos balões de um grupo de crianças de um jardim de infância, uma dupla de estudantes planificou, em contexto de formação na universidade, com a ajuda e orientação do docente, a seguinte sequência de atividades de aprendizagem:

- Transformar o movimento irregular de um balão num movimento retilíneo. De um modo geral, as crianças sabem que um balão cheio de ar, ao ser largado, adquire um movimento irregular, ao mesmo tempo que se esvazia, acabando por se imobilizar no chão. Como transformar o movimento irregular do balão num movimento em linha reta? Depois de compreendido o significado de "movimento em linha reta", é possível que proponham ideias que se revelam infrutíferas. É então necessário ajudá-las a pensar, de forma a construírem coletivamente um dispositivo que permita dar ao balão um movimento retilíneo - “o balão-foguete”. O questionamento do educador e a introdução seletiva dos materiais necessários à construção do dispositivo devem desencadear na criança as seguintes ações: a) passar a linha de pesca pelo interior de uma palhinha de refresco; b) prender a linha entre duas cadeiras, suficientemente afastadas; c) encher um balão com ar e fechar a sua abertura com uma mola para prendedor de roupa; d) colar, com fita-cola, o

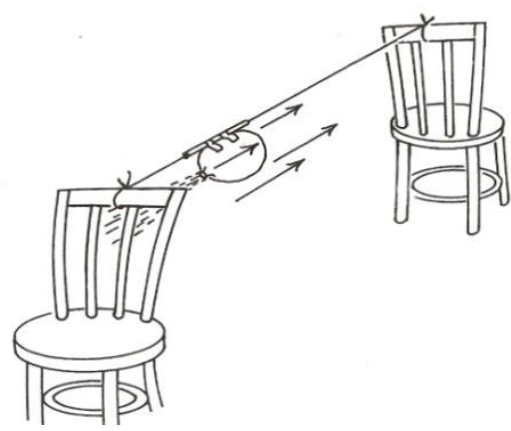

Figura 1 - O balão-foguete in VanCleave (1993). balão cheio de ar na palhinha, com a abertura voltada para a cadeira mais próxima. No final, as crianças devem: elaborar previsões, quanto ao comportamento do balão, ao retirar-se a mola da sua abertura; testar essas previsões; observar que o balão se movimenta ao longo da linha de pesca; e relacionar o sentido do movimento do balão com o sentido da saída do ar.

A deslocação do balão, à medida que o ar vai saindo, baseia-se no princípio da conservação da quantidade de movimento. Segundo este princípio, é constante a quantidade de movimento de um sistema, quando a resultante das forças externas que nele atuam for nula. A quantidade de movimento $(\vec{Q})$ de um corpo é a grandeza vetorial dada pelo produto da massa pela sua velocidade, cuja direção e sentido são os mesmos do vetor velocidade, conforme a expressão seguinte: $\vec{Q}=m \times \vec{v}$. Quando temos um sistema com vários corpos, a quantidade de movimento total do sistema, isolado de forças externas, é obtida pela soma vetorial da quantidade de movimento de cada corpo: $\vec{Q}_{\text {sistema }}=\vec{Q}_{1}+$ $\vec{Q}_{2}+\cdots+\vec{Q}_{3}=$ (constante). Isto não significa que a quantidade de movimento de cada corpo do sistema seja invariável. Apenas a soma o é, pois, se a quantidade de movimento 
de um diminui, a do outro ou dos outros terá de aumentar para compensar essa variação, de modo a que a quantidade de movimento do sistema permaneça constante. Se considerarmos o sistema balão e massa de ar nele contida, a quantidade de movimento total que o sistema possui no início é dada pela soma da quantidade de movimento do balão com a quantidade de movimento do ar. Como ambos estão em repouso - as suas velocidades são nulas, então a quantidade de movimento inicial do sistema é igual a zero: $\vec{Q}_{\text {do sistema antes }}=\vec{Q}_{\text {balão }}+\vec{Q}_{\text {ar }}=0$. Como se explica então o deslocamento do balão, a partir de uma situação de repouso? No momento em que se abre a abertura do balão, o ar começa a sair, ou seja, parte da massa de ar contida no balão passa do estado de repouso a movimento. Não havendo a ação de nenhuma força externa, pois nenhuma pessoa ou qualquer outro agente empurra o balão, então, para que a quantidade de movimento do sistema balão e ar se conserve igual a zero $\left(\vec{Q}_{\text {do sistema depois }}=\vec{Q}_{\text {balão }}+\vec{Q}_{\text {ar }}=0\right)$, é condição que o sistema, balão mais a massa de ar que nele ainda continua, se desloque em sentido contrário à saída do ar: $\vec{Q}_{b a l a ̃ o}=-\vec{Q}_{a r}$. É isso que acontece: a quantidade de movimento correspondente à saída do ar é anulada pela quantidade de movimento correspondente ao avanço do balão, pois são movimentos com sentidos contrários.

- Investigar a influência da quantidade de ar do balão na distância por ele percorrida. As crianças investigam agora a relação entre a quantidade de ar do balão e a distância por ele percorrida. Com ajuda do educador, devem identificar as variáveis que podem influenciar a distância percorrida pelo balão, prever possíveis diferenças, em função da quantidade de ar insuflada no balão, testar essas previsões e, por último, observar e interpretar as observações, concluíndo que, quanto maior a quantidade de ar do balão, maior é a distância que ele percorre.

- Aplicar as aprendizagens realizadas. As aprendizagens anteriores devem ser mobilizadas e aplicadas na construção de um carrinho movido pela saída do ar do interior de um balão.

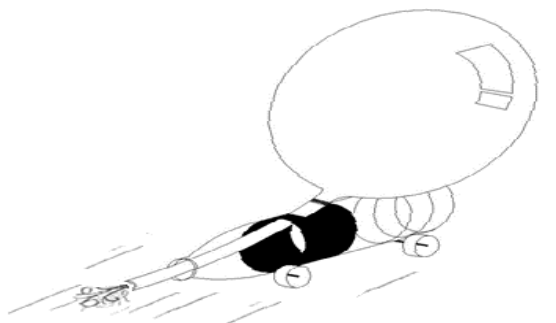

Figura 2 - Carrinho movido a ar. Adaptado de: http://yancao.info/yancaoimages.html

\section{A EXPLORAÇÃO DIDÁTICA DA SEQUÊNCIA DE ATIVIDADES}

É com base no diário das atividades, elaborado pela dupla de estudantes, que se apresenta a análise do processo de exploração da sequência de atividades de aprendizagem, promovido com as crianças da educação pré-escolar.

\section{A. Transformar o movimento irregular de um balão num movimento retilíneo}

A1. O que irá acontecer se largar na sala este balão cheio de ar? 
- As crianças elaboram previsões.

Perante a questão anterior, são unânimes em prever que o balão irá adquirir movimento: "Vai voar" (Rodrigo); "Vai andar" (Sara); "Vai fugir" (Mariana). A causa desse movimento é atribuída à saída do ar do interior do balão: "Porque está cheio de ar" (Sara); "Porque vai sair o ar" (José); "Porque vai esvaziar" (Maria).

A2. O que devemos fazer para sabermos se as vossas respostas estão corretas?

- Sugerem testar as previsões, testam-nas e realizam observações. Excerto do diário:

As crianças sugerem largar o balão: "Deixa o balão" (Várias). "Tens de deixar o balão ir sozinho" (David). O balão é largado no ar da sala. As crianças ficam radiantes com o sucedido e testam elas mesmas as suas ideias, enchendo e largando balões.

- Comunicam as observações. Excerto do diário:

Após a euforia, são incentivadas a comunicar as observações efetuadas sobre o que aconteceu ao balão: "Fugiu" (Mariana); "Voou" (José). "Como foi que o balão "fugiu" ou "voou"? - pergunto. As crianças verbalizam e algumas gesticulam o movimento irregular do balão: "Foi assim às curvas" (Guilherme); "Andou muito torto" (Ana); "Voou às voltinhas" (Joana); "Fez muitas curvas no ar" (Manuel).

As observações das crianças incidem no elemento mais facilmente percetível da situação, o movimento irregular do balão. A saída do ar não é referida, apesar de, anteriormente, a terem assumido como causa desse movimento.

A3. Como transformar o movimento irregular do balão num movimento retilíneo?

- Compreendem o significado da expressão "movimento em linha reta".

As crianças revelam compreender o significado daquela expressão e, gesticulando, comunicam-no da seguinte forma: "É ir assim direitinho, sempre em frente" (António); "É o balão andar direito" (José).

- Sugerem e executam uma estratégia.

Para transformarem o movimento irregular do balão num movimento retilíneo, as crianças apenas sugerem e executam a seguinte estratégia, a qual se revela infrutífera: "atar o balão cheio de ar e atirá-lo na horizontal no ar da sala". Na ausência de outras possibilidades e dado o elevado nível de dificuldade do desafio, as crianças necessitam de ajuda para construírem uma estratégia de resolução eficaz - o "balão-foguete".

- Identificam os materiais necessários à construção do "balão-foguete".

Como forma de ajuda, são fornecidos alguns materiais: uma palhinha de refresco; fita-cola; balões; uma tesoura; uma mola para prendedor de roupa; linha de pesca. As crianças identificam-nos corretamente, à exceção da linha de pesca. 


\section{- Constroem coletivamente, com ajuda, o "balão-foguete". Excerto do diário:}

"Será que esta linha de pesca nos pode ajudar?" - pergunto. Todas afirmam que "sim", sem, no entanto, sugerirem uma nova estratégia. Há quem insista na estratégia anterior, utilizando agora a linha de pesca para atar o balão cheio de ar: "Atas o balão com a linha e dás um nó e depois atiras e ele vai andar direito" (Beatriz). O Gabriel, em tom crítico, refere: "Assim não sai o ar como há bocado". Na ausência de novas ideias, prendo uma das extremidades da linha de pesca ao encosto de uma cadeira. Pego na palhinha de refresco e pergunto o que devemos fazer com ela. "Tens que pôr a palhinha na linha" - refere o Manuel. Quando solicitado, passa a linha pelo interior da palhinha. "O que devemos fazer agora à outra ponta da linha de pesca?" - pergunto. "Prende-se àquela cadeira" - responde a Sara. Depois de presa às duas cadeiras, pergunto: "Acham que este dispositivo vai ajudar o balão a andar em linha reta?" Algumas crianças referem que "não", enquanto a maioria diz que "sim". Porém, mesmo nestas, que respondem afirmativamente, noto a ausência de compreensão sobre a finalidade do dispositivo montado e, por isso, pergunto: como é que ele nos vai ajudar? Após alguns instantes, o António refere: "Acho que vamos pôr, assim, o balão na linha e ele vai depois sempre assim sozinho" (encosta o balão vazio à linha e faz o gesto do movimento que o balão irá ter ao longo desta). O grupo está atento à explicação do António. Dirijo-me para as outras crianças e pergunto-lhes se o balão anda sozinho. "Não, só se pusermos ar" - refere a Beatriz. Encho o balão com ar e pergunto: "E agora como vamos prender o balão?" "Com a mola" - respondem várias crianças. "Pões a mola e depois o ar não sai do balão" (Rodrigo). Com a abertura do balão fechada e presa com a mola, surge um novo problema: como prendê-lo na palhinha de refresco, que se encontra na linha de pesca. Na ausência de respostas e como forma de ajuda, pego na fita-cola e, com o balão na horizontal, encostado à palhinha, pergunto: "E agora o que deveremos fazer?” As crianças sugerem e colam o balão à palhinha, que se encontra na linha de pesca presa às duas cadeiras.

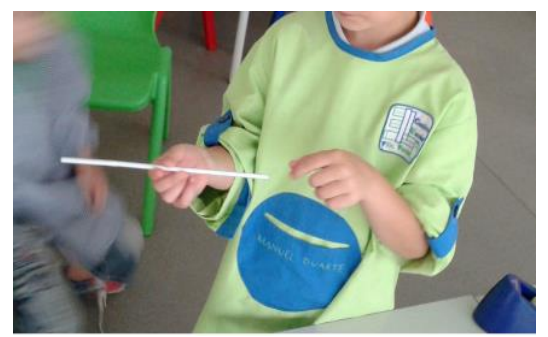

Figura 3 - Criança a passar a linha pelo interior da palhinha.

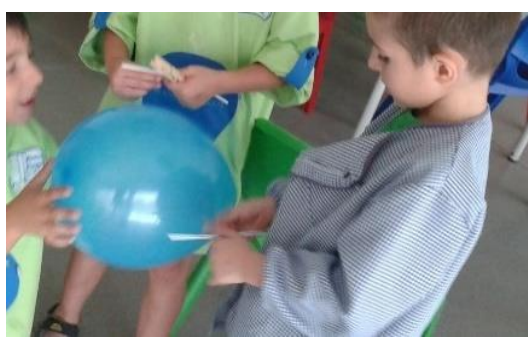

Figura 4 - Crianças colam o balão à palhinha.

A4. O que temos de fazer, agora, para o balão se movimentar?

- Sugerem retirar a mola e preveem o resultado: o movimento retilíneo do balão. 
Facilmente as crianças sugerem retirar a mola do balão, para que a saída do ar do seu interior o faça movimentar em sentido contrário: "Vai andar com a palhinha para o outro lado" (João). A mola é retirada do balão e este percorre todo o trajeto, em linha reta, até à outra extremidade da linha de pesca. $\mathrm{O}$ ambiente na sala é de grande euforia $\mathrm{e}$ contentamento com a resultado obtido.

\section{- Refletem sobre a evidência. Excerto do diário:}

As crianças são estimuladas a pensar. "Quem é que fez andar o balão para a frente?" - pergunto. Prontamente, respondem que "foi o ar que saiu". "Para onde é que ele saiu?". "Foi para ali." - responde a Sara, referindo-se ao sentido oposto ao do movimento do balão. "Saiu pra trás" (Maria). "E o balão para onde se deslocou?" - pergunto. "Andou prá frente" (Rodrigo); "Foi para o outro lado" (Ana). A atividade é repetida e peço a algumas crianças que coloquem a mão na abertura do balão, no momento em que é largado. "O que sentem?" - pergunto. Referem que sentem o "ar a sair para trás".

\section{- Recapitulam oral e coletivamente a atividade realizada.}

Estimuladas a recapitularem o que tinham realizado e observado, as crianças verbalizam de forma clara e sequencial os procedimentos efetuados: "Enchemos o balão, depois colámos e pusemos a mola e largámos; a mola estava virada para aí" - faz o gesto com a mão (Rúben); "Para o balão ir para o outro lado, o ar veio para este lado e o balão foi para o outro" (João).

\section{B. Investigar a influência da quantidade de ar do balão na distância por ele percorrida}

Tendo o balão anterior percorrido todo o trajeto - o comprimento da linha de pesca entre as duas cadeiras, esta atividade iniciou-se com a seguinte questão:

B1. O que devemos fazer, se quisermos que o balão percorra uma distância menor?

\section{- Elaboram um plano mental simplificado. Excerto do diário:}

Algumas crianças respondem prontamente: "Enchemos pouquinho ar"; "Pomos pouquinho ar e ele vai andar só até aqui." Todas concordam com esta ideia e peço-lhes para imaginarem uma "corrida de balões-foguete". "O que devemos fazer?" - pergunto. "Há ali mais cadeiras" (Maria); "Temos muita linha" (Sara); "Põe-se a linha na palhinha" (António). Com estas sugestões, demonstram que a construção anterior ainda se encontra bem presente nas suas mentes. "Como devem ser as quantidades de ar a colocar dentro dos balões?" - pergunto. Perante a ausência de respostas, introduzo nova questão: "Será que devem ser diferentes ou iguais?". Referem que devem ser diferentes e algumas acrescentam: "Temos que encher assim um muito grannnnnde..." (Maria); "E o outro assim pequenino" (Rúben). "E os balões como devem ser?”. Na ausência de respostas, volto a questionar: "Será correto utilizarmos um balão vazio pequenino e um balão vazio 
grande?". Timidamente referem que não, mas, questionadas de novo, afirmam agora, em uníssono, que os balões devem ser "iguais!".

B2. Se fizermos uma corrida de balões, qual irá ganhar?

- Elaboram previsões.

É unânime a previsão de que o balão com maior quantidade de ar no seu interior irá ganhar a corrida, porque "tem mais ar", "está mais cheio".

- Testam as previsões elaboradas. Excerto do diário:

As crianças, com a minha ajuda, constroem outro dispositivo - "balão-foguete", paralelamente ao anterior. "E agora, o que devemos fazer para vermos qual dos balões irá ganhar?" - pergunto. "Tens de prender o balão à palhinha. Vais pôr a mola" (António); "A mola é para o ar não sair" (Beatriz). Peço a duas crianças que encham dois balões com quantidades de ar visivelmente diferentes. Prendo a abertura dos balões com uma mola e pergunto como deverá ser a posição dos balões. "A mola é para ali" - diz a Beatriz, indicando que as aberturas dos balões devem estar viradas para a cadeira mais próxima. "Porquê?" - pergunto. As crianças justificam as suas respostas, dizendo: "porque o ar sai para ali" (para trás) - referem várias. A Ana acrescenta: "porque sai para ali e depois o balão vai para a frente". Solicito a duas crianças que retirem, em simultâneo, as molas dos balões, para se iniciar a corrida. No final, o grupo extravasa reações de contentamento com o resultado da corrida de "balões-foguete".

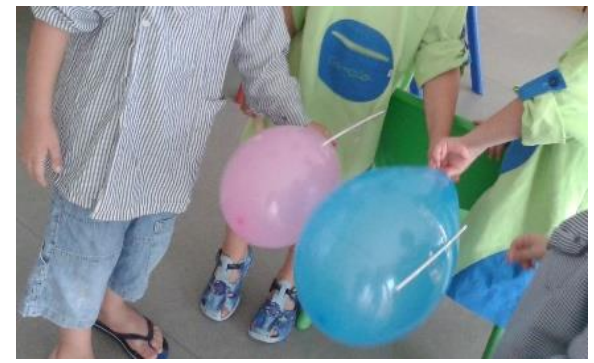

Figura 5 - Balões-foguete no momento da partida da corrida.

- Refletem coletivamente sobre a evidência.

Estimuladas a refletir, as crianças facilmente relacionam a distância percorrida pelos balões com a quantidade de ar neles introduzida: "Este ganhou, porque o outro tinha pouco ar e este tinha mais" (Maria); "Estava muito cheio e depois andou mais" (Beatriz); "Este andou mais, porque tinha mais ar" (Sara).

- Registam e comunicam as aprendizagens.

No final, como forma de registo das aprendizagens realizadas, as crianças elaboram um desenho da atividade e comunicam o seu significado. Exemplos: 
Desenho 1 - Comentário da criança ao seu desenho: "Eu fiz a linha de pesca, os dois balões, as duas molas e as cadeiras. Fiz depois a corrida. Este balão (apontando para o azul) estava muito cheio e chegou ao fim. Ganhou a corrida! O outro tinha pouquinho ar e perdeu, porque andou pouco."

Desenho 2 - Comentário da criança ao seu desenho: "Desenhei a corrida dos balões, eles aqui (os balões cheios junto às cadeiras) estão na partida. Este ganhou (apontando para o primeiro) e o outro perdeu, porque tinha pouco ar."

Desenho 3 - Comentário da criança ao seu desenho: "A linha de pesca presa nas cadeiras e o balão preso com a fita-cola. Quando sai o ar, o balão anda pró outro lado e fica vazio. $\mathrm{O}$ ar faz andar o balão prá frente.”

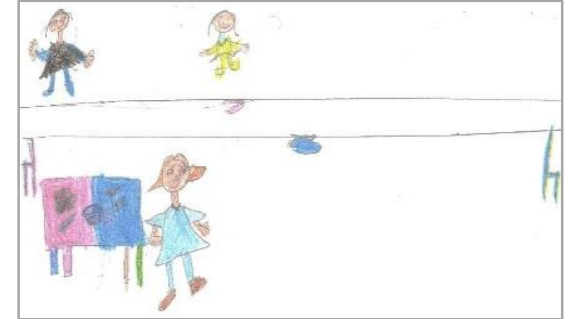

Figura 6 - Desenho 1.

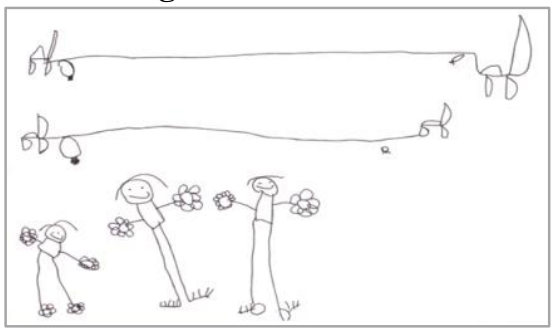

Figura 7 - Desenho 2.

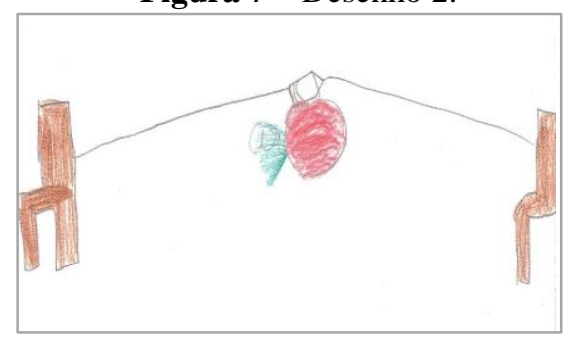

Figura 8- Desenho 3.

\section{Aplicar as aprendizagens a um novo contexto: carrinhos movidos a ar}

As crianças, em pequenos grupos, procedem à montagem de vários carrinhos como o da figura 9, utilizando o seguinte material: uma garrafa pet, previamente cortada; dois paus de madeira para espetada, quatro tampinhas de plástico.

C1. O que devemos fazer para o carrinho andar?

\section{- Aplicam as aprendizagens anteriores.}

A primeira reação das crianças é soprar nos carrinhos: “Sopramos!". Tentam soprar, mas não o conseguem movimentar. Tal reação, para além de impulsiva, poderá evidenciar alguma dificuldade em mobilizarem as aprendizagens anteriores. Como forma de ajuda, o pensamento das crianças é focalizado numa palhinha de refresco e num balão e é evocada, ao plano da consciência das crianças, a atividade do "balão-foguete". Surgem, então, novas ideias que revelam a compreensão das ações a efetuar: "Temos de prender a palhinha ao balão" (António); "Depois sopramos pela palhinha e enchemos o balão" (Joana); "Metemos no carrinho e depois largamos a palhinha" (Rodrigo). Assim fizemos! O carrinho anda e todos entusiasmados festejam a conquista. No final, propõem uma corrida de carinhos movidos a ar, de modo a relacionarem a quantidade do ar do balão com a distância que o carrinho irá percorrer. As previsões elaboradas preveem que, quanto maior for a quantidade de ar no interior do balão, maior será a distância por ele 
percorrida. Testam as suas previsões e refletem sobre as observações efetuadas: "Qual foi o carrinho que andou mais?": "Foi o carrinho do balão amarelo" (Várias); "Foi o amarelo, estava mais cheio"; "O verde andou menos, porque tinha pouco ar" (Beatriz).

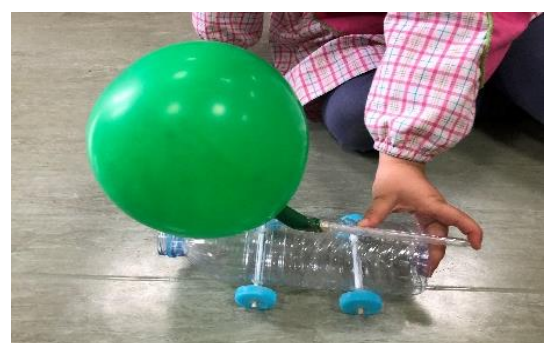

Figura 9 - Carrinho construído com uma garrafa pet.

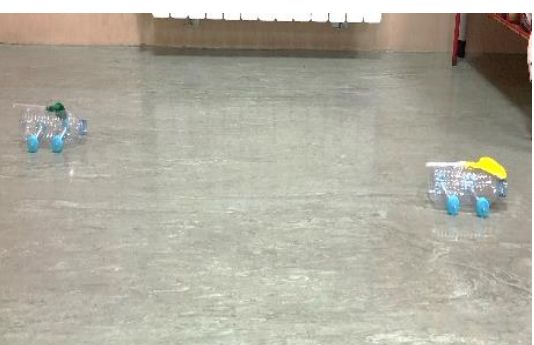

Figura 10 - Corrida de carrinhos movidos a ar.

- Comunicam oralmente as aprendizagens realizadas.

As crianças partilham oralmente as descobertas realizadas, para que sejam, posteriormente, ilustradas e colocadas num cartaz de parede: "O carrinho anda mais, porque o balão está mais cheio" (David); "O carrinho anda mais rápido, quando o balão está mais cheio" (Gabriel); "O carrinho anda menos, porque o balão tem pouco ar" (Sara).

\section{CONSIDERAÇÕES FINAIS}

A análise do processo de exploração da sequência de atividades permite verificar que as crianças destas idades são capazes de assumir uma atitude científica na procura do saber, quando envolvidas em atividades de aprendizagem interessantes e abordadas num contexto colaborativo de estimulação e expressão do seu pensamento. A interação social que se gera entre as crianças e entre estas e o educador, assim como o domínio da linguagem são fundamentais, para que possam atingir elevados níveis de cognição e aprendizagem (ALEIXANDRE, 2003). Desse modo, movidos pelo seu desejo natural de conhecer, tornam-se sujeitos ativos e reflexivos no processo de aprendizagem (FRENCH, 2004, PATRICK; MANTZICOPOULOS, 2015), sugerindo estratégias, propondo e executando um conjunto de processo científicos simples (FRENCH; WOODING, 2013) para procurarem respostas às questões com as quais são confrontadas. Na primeira atividade anteriormente analisada, as crianças são desafiadas a resolverem o problema de como transformarem o movimento irregular de um balão num movimento retilíneo. Para construírem uma solução eficaz, começam por elaborar previsões, a partir das suas experiências prévias, acerca do que acontecerá a um balão cheio de ar, quando largado no ar da sala; testam essas previsões; observam e comunicam oralmente o movimento irregular do balão, depois de largado; compreendem e exprimem o significado da expressão "movimento em linha reta"; sugerem e executam estratégias, apesar de se revelarem infrutíferas; constroem coletivamente, com ajuda, um dispositivo capaz de 
transformar o movimento irregular do balão num movimento retilíneo - "o balãofoguete"; preveem o resultado, o movimento retilíneo do balão; refletem sobre a evidência, relacionando o sentido da saída do ar com o sentido de deslocamento do balão - sentidos opostos; recapitulam oralmente a atividade realizada. Seguidamente, para investigarem a influência da quantidade de ar do balão na distância por ele percorrida, elaboram um plano de investigação simplificado; realizam previsões; testam essas previsões; refletem coletivamente sobre a evidência; registam, através do desenho, e comunicam as aprendizagens. Por último, aplicam as aprendizagens realizadas a um novo contexto, construindo carrinhos movidos com balões cheios de ar e investigando, também, através de uma corrida de carrinhos, a relação entre a quantidade de ar inserida nos balões e a distância percorrida pelos carrinhos.

Todo este processo, que assume um caráter holístico, implica naturalmente um grande envolvimento intelectual e socioafetivo da criança e é indissociável de uma intervenção planificada, estruturada e intencionalmente orientada pela ação do educador (WORTH, 2010), com vista a promover nas crianças novas aprendizagens e a desenvolver, simultaneamente, competências de processos científicos (GERDE et al., 2013; HARLEN, 2012, 2014). Nesse processo, a ação do adulto é fundamental, através dos desafios que coloca à exploração e à descoberta e da ajuda que fornece às dificuldades que as crianças vão sentindo na sua atividade mental construtiva. Neste sentido, a análise do processo de exploração da sequência anterior de atividades revela ainda que a dupla de estudantes, futuras educadoras de infância, realizou uma boa aprendizagem da abordagem investigativa das ciências preconizada para as crianças. A intencionalidade que imprimiram à sua ação educativa é concomitante com uma prática reflexiva, na forma como vão, através de um questionamento estimulador do pensamento e ação das crianças (VAN ZEE; MINSTRELL, 1997), apoiando e regulando a sua atividade cognitiva individual e conjunta, ajudando-as a escalar progressivamente elevados níveis de aprendizagem e cognição (KAWALKAR; VIJAPURKAR, 2013).

Salienta-se ainda a importância que a generalidade das duplas de estudantes atribui ao valor formativo destas experiências pedagógicas no contexto da prática, proporcionando-lhes o estabelecimento de conexões entre o conhecimento teóricodidático explorado na universidade e o aprendido na e a partir dos desafios que a própria prática lhes impõe. Assim, tais experiências, ainda que de curta duração, devem também ser parte integrante do processo de formação inicial, promovido no âmbito das metodologias ou didáticas específicas, de forma a constituírem-se como uma espécie de "terceiro espaço" (ZEICHNER, 2010), que estimule a criação de novas oportunidades de aprendizagem para os educadores e professores em formação. 
Por último, corroboramos a opinião de Appleton (2007), a qual salienta que os cursos de formação de educadores e professores primários devem, em primeiro lugar, proporcionar experiências formativas bem-sucedidas, com atividades de ciências interessantes, a fim de criarem neles uma atitude positiva e a autoconfiança necessária em relação às ciências e à sua exploração com as crianças. Porém, tais experiências formativas devem habilitá-los com um saber fazer específico orientado para a exploração dos diversos tópicos curriculares. O desenvolvimento desse saber deve ser fomentado por um processo de formação, inicial e contínua, apoiado em dados e instrumentos que emerjam da investigação realizada com crianças, nos seus contextos naturais de aprendizagem. A investigação deve proporcionar aos educadores e professores elementos frutuosos de apoio à sua ação educativa. Neste sentido, a análise do processo de exploração da sequência de atividades apresentada neste artigo pode constituir uma ferramenta didática, não restritiva, de apoio ao processo de formação e aos próprios educadores para, em contextos similares, evocarem e promoverem idêntico processo de exploração com as crianças.

\section{AGRADECIMENTOS}

Este trabalho foi financiado pela FCT - Fundação para a Ciência e a Tecnologia no âmbito do projeto do CIEC (Centro de Investigação em Estudos da Criança da Universidade do Minho) com a referência UID/CED/00317/2019.

Cofinanciado por: UID/CED/00317/2019

\section{FCT Fundação para a Ciência e a Tecnologia MINISTÉRIO DA EDUCAÇÃO E CIÊNCIA.}

\section{REFERÊNCIAS}

ALEIXANDRE, J. M. Comunicación y lenguaje. In: ALEIXANDRE, J. M. (Ed.), Enseñar ciencias. Barcelona: Editorial Graó, 2003, p. 55-71.

APPLETON, K. (2007). Elementary science teaching. In: ABELL, S. K.; LEDERMANN, N. G. (Eds.), Handbook of Research on Science Education. Mahwah: Lawrence Erlbaum Associates, 493- 536.

BULUNUZ M. Developing Turkish preservice preschool teachers' attitudes and understanding about teaching science through play. International Journal of Environmental \& Science Education, v.7, n.2, p. 141-166, 2012.

DOMÉNECH, J.; PRO BUENO, A.; SOLBES, J. ¿Qué ciencias se enseñan y cómo se hace en las aulas de educación infantil? La visión de los maestros en formación inicial. Enseñanza de las 
ciencias: revista de investigación y experiencias didáctica, v. 34, n. 3, p. 25-50, 2016. DOI: https://doi.org/10.5565/rev/ensciencias.1870

ESHACH, H.; FRIED, M. Should science be taught in early childhood? Journal of Science Education and Technology, v. 14, n. 3, p. 315-336, 2005.

FIOLHAIS, C. De pequenino é que se torce o destino: ciência no jardim-de-infância. Cadernos de educação de infância, v. 95, p. 49-54, 2012.

FRENCH, L. Science as the center of a coherent, integrated early childhood curriculum. Early Childhood Research Quarterly, v. 19, n. 1, p. 138-149, 2004.

FRENCH, L.; WOODING, S. Science education in the early years. In: SARACHO, O.; SPODEK, B. (Eds.), Handbook of research on the education of young children. New York: Routledge, 2013, p. 179-196.

FURMAN, M. O ensino de Ciências no Ensino Fundamental: colocando as pedras fundacionais do pensamento científico. Vila Siqueira: Sangari Brasil, 2009.

GERDE, H.; PIERCE, S.; LEE, K.; VAN EGEREN, L. Early Childhood Educators' Self-Efficacy in Science, Math, and Literacy Instruction and Science Practice in the Classroom. Early $\begin{array}{lllllllll}\text { Education and Development, } & \text { v. 29, } & \text { n. } & 1, & \text { p. } & 70-90, & 2018 . & \text { DOI: }\end{array}$ https://doi.org/10.1080/10409289.2017.1360127

GERDE, H.; SCHACHTER, R.; WASIK, B. Using the Scientific Method to Guide Learning: An Integrated Approach to Early Childhood Curriculum. Early Childhood Education Journal, v. 41, n. 5, p. 315-323, 2013. DOI: https://doi.org/10.1007/s10643-013-0579-4

GRAUE, M. E.; WALSH, D. J. Investigação Etnográfica com Crianças: Teorias, métodos e ética. Lisboa: Fundação Calouste Gulbenkian, 2003.

HAMLIN, M.; WISNESKI, D. Supporting the scientific thinking and inquiry of toddlers and preschoolers through play. Young Children, v. 67, n. 3, p. 82-88, 2012.

HARLEN, W. Helping children's development of inquiry skills. Inquiry in primary science education, v. 1, p. 5-19, 2014.

HARLEN, W. Inquiry in Science Education. Background resources for implementing inquiry in science and mathematics at school, 2012. Disponível em: http://fibonacci.unibayreuth.de/resources/resources-for-implementing-inquiry.html

HARLEN, W.; ALLENDE, J. Teacher Professional Development in Pre-Secondary School Inquiry-Based Science Education (IBSE). Santiago, Chile: FEBAFM, 2009. Disponível em: https://www.interacademies.org/31842/Publications

HEYWOOD, D.; PARKER.J. (2010). The Pedagogy of Physical Science. London: Springer.

IAP - InterAcademy Panel, Report of the Working Group on International Collaboration in the Evaluation of Inquiry-Based Science (IBSE) Programs. Santiago, Chile: FEBAFM, 2006. 
KAWALKAR, A.; VIJAPURKAR, J. Scaffolding Science Talk: The role of teachers' questions in the inquiry classroom. International Journal of Science Education, v. 35, n. 12, p. 20042027, 2013. DOI: https://doi.org/10.1080/09500693.2011.604684

LEITE, F. Diário de Bordo em aulas de Epistemologia: contribuições na formação inicial de professores de Química. Revista Insignare Scientia, v. 2, n. 3, p. 125-133, 2019. DOI: https://doi.org/10.36661/2595-4520.2019v2i3.11191

MARTINS, I. et al. Despertar para a ciência - actividades dos 3 aos 6. Lisboa: ME, 2009.

NAYFELD, I.; BRENNEMAN, K.; GELMAN, R. Science in the Classroom: Finding a Balance Between Autonomous Exploration and Teacher-Led Instruction in Preschool Settings. Early Education and Development, v. 22, n. 6, p. 970-988, 2011. DOI: https://doi.org/10.1080/10409289.2010.507496

PATRICK, H.; MANTZICOPOULOS, P. Young Children`s Motivation for Learning Science. In: Trundle, K.; Saçkes, M. (Eds.), Research in Early Childhood Science Education. New York: Springer, 2015, p. 35-66.

PRI-SCI-NET. Primary Science Network. This project has received funding from the European Union's Seventh Framework Programme, 2014. Disponível em: http://prisci.net/

REIS, P. Investigar e Descobrir Actividades para a Educação em Ciências nas Primeiras Idades. Chamusca: Cosmos, 2008.

SÁ, J. (2003). Ciências experimentais na educação pré-escolar e $1^{\circ}$ ciclo do ensino básico: perspetivas de formação de professores. In: VEIGA, L. (Ed.), Formar para a Educação em Ciências na educação pré-escolar e no $1^{\circ}$ ciclo do ensino básico. Coimbra: IPC, 2003, p.45-78.

SAÇKES, M. How often do early childhood teachers teach science concepts? Determinants of the frequency of science teaching in kindergarten. European Early Childhood Education $\begin{array}{lllllllll}\text { Research Journal, } & \text { v. } & 22, & \text { n. } & 2, & \text { p. } & 169-184, & \text { DOI: }\end{array}$ https://doi.org/10.1080/1350293X.2012.704305

SMITH, K. Working scientifically: a guide for primary science teachers. London: David Fulton, 2016.

TRUNDLE, K. The Inclusion of Science in Early Childhood Classrooms. In: TRUNDLE, K.; SAÇKES, M. (Eds.), Research in Early Childhood Science Education. New York: Springer, 2015, p. 1-6.

TRUNDLE, K.; SAÇKES, M. Science and Early Education. In: PIANTA, R. (Ed.), Handbook of Early Childhood Education. New York: The Guilford Press, 2012, p. 240-258.

UNESCO. A ciência para o século XXI: uma nova visão e uma base de ação. Budapeste e Santo Domingo. Brasília: UNESCO Brasil, 2005.

VAN ZEE, E.; MINSTRELL, J. Using Questioning to Guide Student Thinking, Journal of the Learning Sciences, v. 6, n. 2, p. 227-269, 1997.

VANCLEAVE, J. Física para jovens. Lisboa: Publicações Dom Quixote, 1993. 
WORTH, K. Science in Early Childhood Classrooms: Content and Process. Early Childhood Research \& Practice, v. 12, n. 2, 2010.

ZABALZA, M. Diarios de clase: un instrumento de investogación. Madrid: Narcea, 2004.

ZEICHNER, K. Rethinking the Connections Between Campus Courses and Field Experiences in College- and University-Based Teacher Education. Journal of Teacher Education, v. 61, n. 12, p. 89-99, 2010. DOI: https://doi.org/10.1177/0022487109347671 